\title{
Trust in science, social consensus and vaccine confidence
}

\author{
Patrick Sturgis $\oplus^{1 凶}$, lan Brunton-Smith ${ }^{2}$ and Jonathan Jackson $\circledast^{1,3}$
}

\begin{abstract}
While scholarly attention to date has focused almost entirely on individual-level drivers of vaccine confidence, we show that macro-level factors play an important role in understanding individual propensity to be confident about vaccination. We analyse data from the 2018 Wellcome Global Monitor survey covering over 120,000 respondents in 126 countries to assess how societal-level trust in science is related to vaccine confidence. In countries with a high aggregate level of trust in science, people are more likely to be confident about vaccination, over and above their individual-level scientific trust. Additionally, we show that societal consensus around trust in science moderates these individual-level and country-level relationships. In countries with a high level of consensus regarding the trustworthiness of science and scientists, the positive correlation between trust in science and vaccine confidence is stronger than it is in comparable countries where the level of social consensus is weaker.
\end{abstract}

$\mathrm{T}$ here is much that we still do not understand about the novel coronavirus, but on one central issue, there is near-universal consensus: the world will not return to anything approaching normal life until an effective and comprehensive global programme of vaccination has been successfully implemented. An intense international effort is now underway to deliver this key objective, with nine vaccines having received regulatory approval at the time of writing and vaccination programmes being rolled out in many countries across the world ${ }^{1}$. But even though this Herculean endeavour has been delivered over a timescale unprecedented in the history of vaccine development, it will not on its own be sufficient to free the world from the grip of the pandemic. For, unlike other medicines, vaccines must work at both the individual and the societal levels to be effective at eliminating viral infections-without high rates of population immunization, the virus is likely to remain endemic ${ }^{2}$. While the exact threshold is not yet known, it seems that it will be necessary for countries to achieve a vaccination rate of over $70 \%$ to attain 'herd immunity' against the coronavirus ${ }^{3}$.

Worryingly in this regard, survey evidence suggests that substantial minorities in many countries may refuse to be inoculated against COVID-19 (ref. ${ }^{4}$ ). A cross-national survey carried out in May 2020 by Kantar found, for example, that $19 \%$ of the US public said they would probably or definitely not get vaccinated, with corresponding figures of $14 \%, 23 \%$ and $24 \%$ in the United Kingdom, Germany and France, respectively ${ }^{5}$. More recently, a survey by Imperial College London in November 2020 found only minorities of the public reporting that they would definitely get vaccinated against COVID-19 in Canada, Germany, Japan, Singapore and France 6 . While hypothetical survey questions are often a poor guide to future behaviour, in the case of vaccination there are good reasons to assume that these figures may represent broadly accurate estimates of rates of vaccine refusal. This is because, despite their unrivalled success in limiting the spread of viral infections around the world ${ }^{7}$, there is a long history of public scepticism about and resistance to mass inoculation programmes.

If the global challenge of widespread immunization against the coronavirus is to succeed, it is crucial that we better understand the social, economic and psychological factors that encourage or inhibit vaccine uptake. Our objective in this article is to contribute to this pressing endeavour by assessing the role of societal-level trust in science in fostering public confidence in vaccination programmes. To date, scholarly attention has focused almost entirely on individual-level trust in science and medical professionals within single-country contexts, with a wealth of evidence showing that trust in science serves as a key psychological factor underpinning vaccine acceptance?

Our primary interest here, though, is in how societal-level scientific trust is associated with vaccination uptake-is the average level of trust in science in a country positively related to vaccine confidence, over and above the individual-level relationship? It is common in hierarchically structured social systems for a variable to have additional complementary or even divergent effects at the individual and macro levels ${ }^{10}$. For example, in the United States, richer voters generally support the Republican Party within states, while wealthier states tend to lean Democrat ${ }^{11}$. The importance of considering the possibility of macro-level influences in addition to individual-level relationships has also been demonstrated for attitudinal variables, with Fairbrother ${ }^{12}$, for instance, finding a strong positive association between country-level political trust and support for environmental protection policies, net of the positive contribution of individual-level political trust.

In addition to considering how country-level differences in average levels of trust in science are related to vaccine confidence, an important contribution of our paper is to assess the role of societal consensus about the trustworthiness of science and scientists, operationalized as the variability in trust assessments around the national averages. There are good reasons to believe that the level of societal consensus in trust assessments may differ quite substantially across locales ${ }^{13}$ and that such differences may be consequential for individual and societal responses to the perception and assessment of risks ${ }^{14}$. Recent work in criminology, for example, has shown that the extent of public consensus on the level of collective efficacy in local neighbourhoods plays an important role in moderating how individual assessments of neighbourhood characteristics affect perceptions of crime risk ${ }^{15}$. People look to the attitudes and behaviours of others to determine what is normal, beneficial and accepted, and

'Department of Methodology, London School of Economics and Political Science, London, UK. ²Department of Sociology, University of Surrey, Guildford, UK. ${ }^{3}$ University of Sydney Law School, Camperdown, New South Wales, Australia. ${ }^{凶}$ e-mail: p.sturgis@lse.ac.uk 


\begin{tabular}{|c|c|c|c|c|}
\hline & B & s.d. & \multicolumn{2}{|c|}{$95 \%$ credible interval } \\
\hline \multicolumn{5}{|l|}{ Fixed effects } \\
\hline \multicolumn{5}{|l|}{ Location (mean) equation } \\
\hline Intercept & -0.014 & 0.022 & -0.058 & 0.030 \\
\hline \multicolumn{5}{|l|}{ Country predictors } \\
\hline Gross domestic product & 0.123 & 0.029 & 0.065 & 0.18 \\
\hline $\begin{array}{l}\text { Harmonized Learning } \\
\text { Outcome }\end{array}$ & -0.052 & 0.033 & -0.117 & 0.014 \\
\hline Gini coefficient & -0.092 & 0.025 & -0.141 & -0.043 \\
\hline \multicolumn{5}{|l|}{ Individual predictors } \\
\hline Male & 0.046 & 0.005 & 0.037 & 0.055 \\
\hline Age (10 yr intervals) & -0.004 & 0.001 & -0.006 & -0.001 \\
\hline Medium education & 0.052 & 0.006 & 0.039 & 0.064 \\
\hline High education & 0.205 & 0.008 & 0.189 & 0.221 \\
\hline Income (logged) & 0.035 & 0.004 & 0.028 & 0.042 \\
\hline \multicolumn{5}{|c|}{ Scale (standard deviation) equation } \\
\hline Intercept & -0.189 & 0.011 & -0.210 & -0.168 \\
\hline \multicolumn{5}{|l|}{ Country predictors } \\
\hline Gross domestic product & -0.011 & 0.013 & -0.036 & 0.015 \\
\hline $\begin{array}{l}\text { Harmonized Learning } \\
\text { Outcome }\end{array}$ & -0.034 & 0.015 & -0.063 & -0.004 \\
\hline Gini coefficient & 0.032 & 0.011 & 0.009 & 0.054 \\
\hline \multicolumn{5}{|l|}{ Individual predictors } \\
\hline Male & 0.032 & 0.004 & 0.023 & 0.040 \\
\hline Age (10 yr intervals) & 0.012 & 0.001 & 0.009 & 0.014 \\
\hline Medium education & -0.136 & 0.005 & -0.146 & -0.126 \\
\hline High education & -0.155 & 0.007 & -0.169 & -0.141 \\
\hline Income (logged) & -0.036 & 0.003 & -0.042 & -0.03 \\
\hline \multicolumn{5}{|l|}{ Random effects } \\
\hline $\begin{array}{l}\text { Standard deviation } \\
\text { (location) }\end{array}$ & 0.253 & 0.017 & 0.222 & 0.289 \\
\hline $\begin{array}{l}\text { Standard deviation } \\
\text { (scale) }\end{array}$ & 0.114 & 0.008 & 0.100 & 0.131 \\
\hline $\begin{array}{l}\text { Correlation of location } \\
\text { and scale }\end{array}$ & 0.140 & 0.091 & -0.041 & 0.316 \\
\hline
\end{tabular}

The data are from the 2018 Wellcome Global Monitor survey. All variables were standardized prior to inclusion in the model. Individual $N=124,529$; country $N=126$. The reported results present the means (B), standard deviations (s.d.) and $95 \%$ credible intervals of the 40,000 monitoring iterations pooled across the four chains. A total of 40,000 warm-up iterations were discarded.

when the normative principle about the positive or negative value of an agent or institution such as scientists and science is widely held, there will be a stronger social influence on individual assessments of what is and is not socially acceptable or appropriate ${ }^{16}$.

How, then, is trust in science related to vaccine acceptance? In its modern incarnation, epidemiologists refer to scepticism about the safety and health benefits of vaccination as 'vaccine hesitancy ${ }^{17}$, defined as "[a] delay in acceptance or refusal of vaccines despite availability of vaccine services" ${ }^{\prime 1}$. According to the WHO's $3 \mathrm{Cs}$ model, the propensity to be vaccine hesitant is a function of three factors: complacency, convenience and confidence ${ }^{19}$. Complacency results, in an unfortunate irony, from the success of vaccination programmes in eliminating viral epidemics, which leads individuals to discount the risk of infection and the need for protection through inoculation. Convenience relates to practical and logistical barriers to accessing vaccines such as cost, location, availability of transport links and the quality of facilities, which, collectively or in isolation, influence hesitancy to be vaccinated.

The vaccine confidence component of this triumvirate, which is our focus here, is the extent to which people believe that vaccines are safe, effective and consistent with their religious beliefs ${ }^{20}$. Vaccine confidence derives from the trust that individuals have in the systems, institutions and actors that produce and deliver immunization programmes ${ }^{21}$. This includes trust in the legitimacy of the political institutions that propose and provide the legal and regulatory frameworks for mass vaccination, in the health-care systems and workers that deliver vaccines on the ground, and in the science that underpins vaccine efficacy and safety ${ }^{22}$. As in other contexts where science and technology intersect with daily lives, most citizens do not have the time, expertise or inclination to assess for themselves the risks and hazards arising from mass inoculation programmes. For this reason, trust in the technical competence and social responsibility of scientific experts is a crucial (if implicit) underpinning for citizen and societal decision-making on vaccination. Trust in science and scientists thus serves as an efficient heuristic shortcut to determining an appropriate judgement about the safety, effectiveness and importance of vaccination that would otherwise require costly and error-prone cognitive processing for individuals ${ }^{23-25}$.

This then accounts for how individual-level assessments of the trustworthiness of science are related to vaccine confidence. But how is trust in science at the societal level related to individual confidence in vaccination programmes? The proposed mechanism here is not that people have a conscious or explicit mental representation of the level and variability of trust among their fellow citizens (although this may be true for some people). Rather, they acquire informal impressions of how science is valued or contested through local social interactions, media representations, and cultural and political debate, and these factors combine to shape individual assessments of the trustworthiness of science ${ }^{26,27}$. It is well known that trust is facilitated in trusting environments ${ }^{28,29}$. In short, instead of costly information processing, people rely on heuristics about the trustworthiness of science, and this tendency is likely to be more pronounced when there is a strong societal consensus about the value, utility and safety of science and technology.

This is because the same social pressures that lead individuals to converge toward the normative consensus in society on science are also likely to encourage people to conform to widely shared beliefs about the benefits and risks of vaccination. In a country where there is a strong social consensus that science can be trusted, we therefore expect vaccination confidence to be high. Conversely, in a country where there is a social consensus that science and scientists are not trustworthy, we expect vaccination confidence to be low. What applies at the macro level we also expect to manifest for individual-level trust-that is, people's assessments of the trustworthiness of scientists will have a stronger positive association with vaccine confidence in countries with a high level of social consensus that trust in science is the normatively appropriate assessment to make of these actors.

\section{Results}

As described in the Methods, our analysis comprises three steps. First, we derive a measure of trust in science using an item response theory (IRT) model fitted to seven items tapping different aspects of trust in science. Second, we fit location-scale models predicting between-individual and between-country heterogeneity in the mean and standard deviation of trust in science, controlling for individual and country-level characteristics. Third, we take the country-specific residuals for the mean and standard deviation of trust from this first-step model and include them as predictors in a multilevel model, where the outcome is individual-level vaccine confidence. In this final model, we assess the individual-level and 


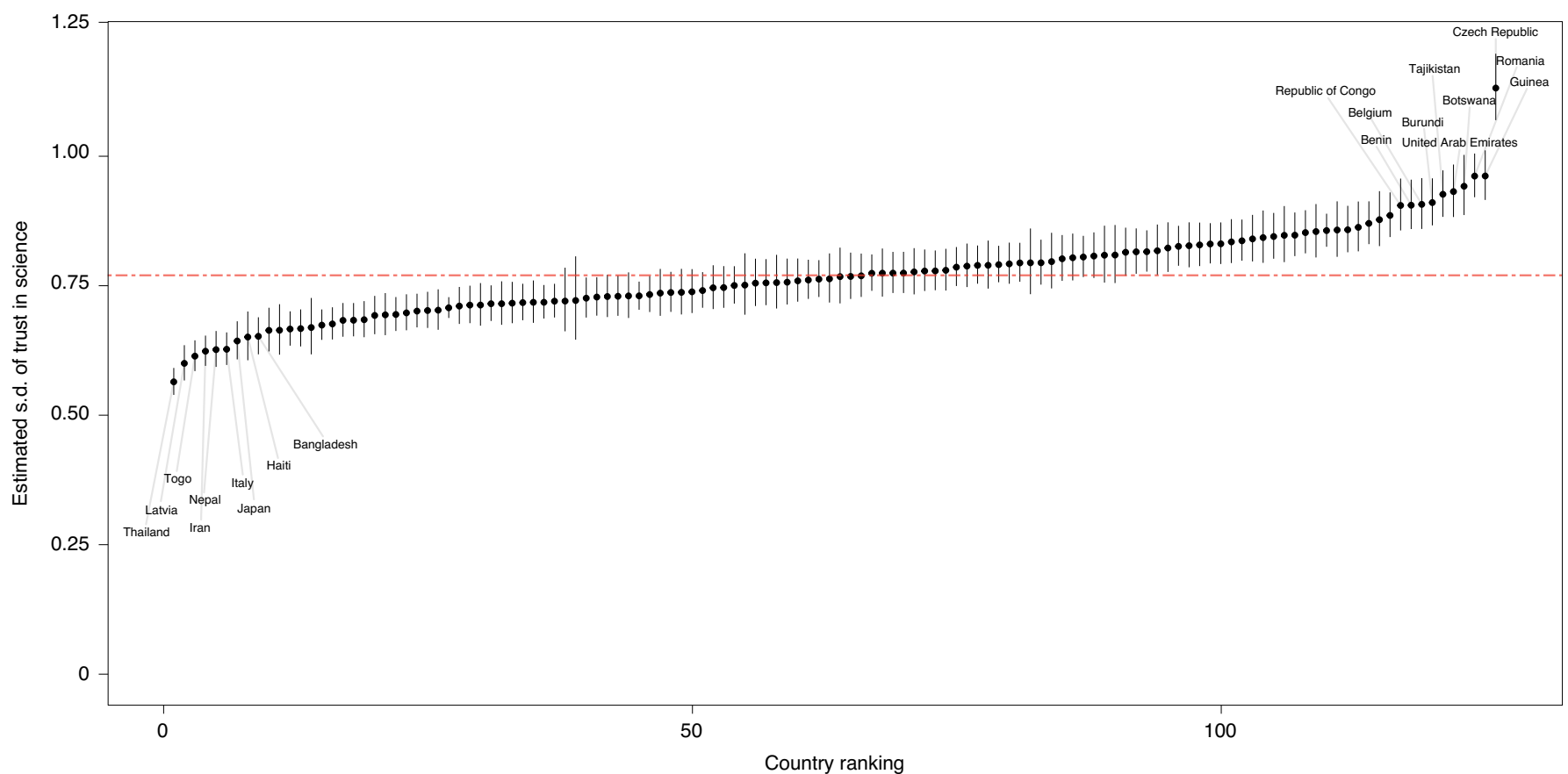

Fig. 1 | Strength of consensus around trust in science across countries. Data are from the 2018 Wellcome Global Monitor survey $(N=124,529)$. The chart shows point estimates and $95 \%$ credible intervals of fitted values from the scale equation model in Table 1 . The horizontal dashed line is the global mean of s.d. across countries. We identify the countries with the lowest and highest estimated within-country standard deviations.

country-level associations between trust in science and vaccine confidence, including their interactions with the level of societal consensus. Before reporting the results of these models, we briefly describe how our measure of trust in science is distributed across countries in the Wellcome Global Monitor.

As has been reported elsewhere ${ }^{30}$, the Wellcome Global Monitor reveals a high level of trust in science globally, with more than four-fifths of people around the world reporting "some" or "a lot" of trust in science, and similar numbers reporting this level of trust in scientists (76\%) and their ability to find out accurate information about the world (81\%). Note that for global estimates, we apply a weight to account for differences in population size between countries. These global averages are underpinned by considerable heterogeneity, with countries accounting for $12 \%$ of the total variance in individual-level scientific trust. Trust in science is highest in North America, western Europe and Australasia and lowest in South America, eastern Europe and Africa. Vaccine confidence is even higher than trust in science, with $92 \%$ of people globally agreeing that vaccines are important for children to have, $78 \%$ that vaccines are safe and $84 \%$ that vaccines are effective. Vaccine confidence also varies considerably across countries, with $18 \%$ of the total variation in confidence between individuals attributable to between-country differences. The highest levels of vaccine confidence are found in Africa and parts of Asia and the lowest levels in eastern Europe.

The results of the location-scale models are presented in Table 1. The top part of the table presents the results from the location (mean) equation, showing how mean levels of trust in science differ across the individual and country covariates. Trust in science is higher in wealthier countries and in countries where income inequality is lower. Men, people with more education and people with higher incomes also report more trust in science. The bottom part of Table 1 shows the results from the scale (standard deviation) equation, with positive values indicating a higher within-country standard deviation and negative values a lower within-country standard deviation. The social consensus on trust in science is substantially stronger (that is, the within-country standard deviation is lower) in countries with higher levels of formal education and with lower levels of income inequality. Within countries, social consensus around trust in science is greater among more educated people and those with higher incomes. Having conditioned on these country and individual level covariates, countries still vary substantially in levels of consensus, with a scale residual of 0.114 . This variability is largely unrelated to a country's mean level of trust in science, with a correlation of 0.140 between the mean and scale residuals.

Figure 1 shows the estimated within-country standard deviations for trust in science, summarizing the extent to which social consensus around trust in science varies across countries (the spread of the country standard deviations is summarized by the scale residual of 0.114). On average, the standard deviation of trust in science across countries is 0.83 (indicated by the horizontal red dashed line), ranging from a minimum of 0.61 to a maximum of 1.22 , with many of the between-country differences significant at the $95 \%$ level of confidence. Note that higher scores in Fig. 1 indicate more within-country variability and therefore a weaker social consensus on trust in science. The Czech Republic has the lowest social consensus on trust, and Guinea, Romania, Botswana and the United Arab Emirates also show notably low levels of agreement about whether science can be trusted. At the other end of the spectrum, Thailand, Latvia, Togo, Iran, Nepal, Italy and Japan have the highest national consensus on trust in science. There is no obvious regional, political, religious or economic pattern to these country groupings.

Turning now to the second-step model, we test for a moderating relationship between social consensus and the mean level of trust in science by including the residuals from the first-stage model as predictors of support for vaccination, with their main effects interacting with the strength of social consensus (the scale equation residual). The parameter estimates are presented in Table 2 for the combined responses to the vaccine confidence items and for each of the three items separately. For each outcome, model a includes the country-level and individual-level main effects of trust in science, and model $b$ adds their interactions with the strength of societal consensus on trust in science. For the overall vaccine confidence 
Table 2 | Interaction model for consensus, trust in science and vaccine confidence

\begin{tabular}{|c|c|c|c|c|c|c|c|c|c|c|c|c|}
\hline & \multicolumn{3}{|c|}{ Model 1a } & \multicolumn{3}{|l|}{ Model 1b } & \multicolumn{3}{|c|}{ Model 2a } & \multicolumn{3}{|l|}{ Model 2b } \\
\hline & Logit & $P$ & $\begin{array}{l}95 \% \\
\text { confidence } \\
\text { interval }\end{array}$ & Logit & $P$ & $\begin{array}{l}95 \% \\
\text { confidence } \\
\text { interval }\end{array}$ & Logit & $P$ & $\begin{array}{l}95 \% \\
\text { confidence } \\
\text { interval }\end{array}$ & Logit & $P$ & $\begin{array}{l}95 \% \\
\text { confidence } \\
\text { interval }\end{array}$ \\
\hline & \multicolumn{6}{|c|}{ Vaccine confidence (combined measure) } & \multicolumn{6}{|c|}{ Important for children } \\
\hline Intercept & 1.197 & $<0.001$ & $\begin{array}{l}1.054 \text { to } \\
1.339\end{array}$ & 1.219 & $<0.001$ & $\begin{array}{l}1.077 \text { to } \\
1.360\end{array}$ & 3.116 & $<0.001$ & $\begin{array}{l}2.913 \text { to } \\
3.318\end{array}$ & 3.151 & $<0.001$ & $\begin{array}{l}2.951 \text { to } \\
3.351\end{array}$ \\
\hline $\begin{array}{l}\text { Trust in science } \\
\text { (country mean, } \hat{u}_{j}^{[1]} \text { ) }\end{array}$ & 0.895 & 0.003 & $\begin{array}{l}0.309 \text { to } \\
1.481\end{array}$ & 0.781 & 0.009 & $\begin{array}{l}0.193 \text { to } \\
1.369\end{array}$ & 0.608 & 0.151 & $\begin{array}{l}-0.221 \text { to } \\
1.437\end{array}$ & 0.434 & 0.304 & $\begin{array}{l}-0.394 \text { to } \\
1.261\end{array}$ \\
\hline $\begin{array}{l}\text { Strength of consensus } \\
\left(\hat{u}_{j}^{[2]}\right)\end{array}$ & & & & 0.455 & 0.498 & $\begin{array}{l}-0.862 \text { to } \\
1.771\end{array}$ & & & & 0.481 & 0.611 & $\begin{array}{l}-1.370 \text { to } \\
2.331\end{array}$ \\
\hline $\begin{array}{l}\text { Trust } \\
(\text { mean }) \times \text { strength of } \\
\text { consensus }\end{array}$ & & & & -5.157 & 0.044 & $\begin{array}{l}-10.184 \text { to } \\
-0.130\end{array}$ & & & & -8.464 & 0.017 & $\begin{array}{l}-15.41 \text { to } \\
-1.518\end{array}$ \\
\hline \multirow[t]{3}{*}{ Country } & 0.66 & & & 0.64 & & & 1.30 & & & 1.23 & & \\
\hline & Model 3 & & & Model 3b & & & Model & & & Model 4b & & \\
\hline & \multicolumn{6}{|c|}{ Vaccines are safe } & \multicolumn{6}{|c|}{ Vaccines are effective } \\
\hline Intercept & 1.535 & $<0.001$ & $\begin{array}{l}1.374 \text { to } \\
1.697\end{array}$ & 1.552 & $<0.001$ & $\begin{array}{l}1.399 \text { to } \\
1.719\end{array}$ & 1.911 & $<0.001$ & $\begin{array}{l}1.771 \text { to } \\
2.051\end{array}$ & 1.934 & $<0.001$ & $\begin{array}{l}1.796 \text { to } \\
2.073\end{array}$ \\
\hline $\begin{array}{l}\text { Trust in science } \\
\text { (individual) }\end{array}$ & 0.505 & $<0.001$ & $\begin{array}{l}0.486 \text { to } \\
0.525\end{array}$ & 0.515 & $<0.001$ & $\begin{array}{l}0.496 \text { to } \\
0.535\end{array}$ & 0.551 & $<0.001$ & $\begin{array}{l}0.529 \text { to } \\
0.573\end{array}$ & 0.558 & $<0.001$ & $\begin{array}{l}0.537 \text { to } \\
0.580\end{array}$ \\
\hline $\begin{array}{l}\text { Trust in science } \\
\text { (country mean, } \hat{u}_{j}^{[1]} \text { ) }\end{array}$ & 1.144 & $<0.001$ & $\begin{array}{l}0.482 \text { to } \\
1.806\end{array}$ & 1.062 & 0.002 & $\begin{array}{l}0.370 \text { to } \\
1.700\end{array}$ & 0.629 & 0.0322 & $\begin{array}{l}0.053 \text { to } \\
1.204\end{array}$ & 0.503 & 0.085 & $\begin{array}{l}-0.070 \text { to } \\
1.077\end{array}$ \\
\hline Country & 0.84 & & & 0.81 & & & 0.63 & & & 0.60 & & \\
\hline
\end{tabular}

The data are from the 2018 Wellcome Global Monitor survey. All tests are two-tailed. For the combined measure, country $N=126$ and individual $N=108,764$; for 'important for children', country $N=126$ and individual $N=113,494$; for 'vaccines are safe', country $N=126$ and individual $N=111,022$; and for 'vaccines are effective', country $N=126$ and individual $N=111,116$.

measure, people who are more trusting of science and scientists are also more vaccine confident $(z=54.3$; d.f. $=1 ; P<0.001$; two-tailed; logit $=0.489$; confidence interval, 0.472-0.507).

Even controlling for this individual-level relationship, people in countries with higher average levels of trust in science are also more confident about vaccination ( $z=2.99$; d.f. $=1 ; P=0.004$; two-tailed; logit $=0.895$; confidence interval, 0.301-1.481). We therefore find support for a positive macro-level relationship between public trust in science and how confident individuals are about vaccination. Model 2 shows that these individual-level and macro-level relationships are moderated by the strength of societal consensus around trust in science-at higher levels of public consensus that science is trustworthy, the strength of the association between trust and confidence is greater for both individual-level and country-level trust in science. The same patterns are also evident for the each of the three vaccine confidence items considered separately.

These interactions are easier to process visually. Figure 2 (top panel) plots the fitted values from model $2 \mathrm{a}$ in Table 2 by the country-level average trust in science ( $x$ axis) and vaccine confidence
( $y$ axis). Figure 2 reveals a substantial difference in the strength of the association between country-level trust in science and vaccine confidence; the average level of trust in science is positively related to vaccine confidence only when the social consensus on trust in science is strong (left panels). In countries where disagreement about trust in science is more prevalent (right panels), the average level of trust in science is not significantly associated with vaccine confidence. The same moderating relationship is also evident for individual-level trust within countries (Fig. 2, lower panel). This cross-level interaction shows that the association between individual trust in science and vaccine confidence is stronger when there is more societal agreement that science and scientists can be trusted, although the substantive magnitude of this interaction is considerably weaker than what is evident at the macro level.

\section{Discussion}

As the world waits impatiently for vaccines to quell the coronavirus pandemic, attention is intensely focused on the speed and efficiency of the nascent inoculation programmes being rolled out in countries 

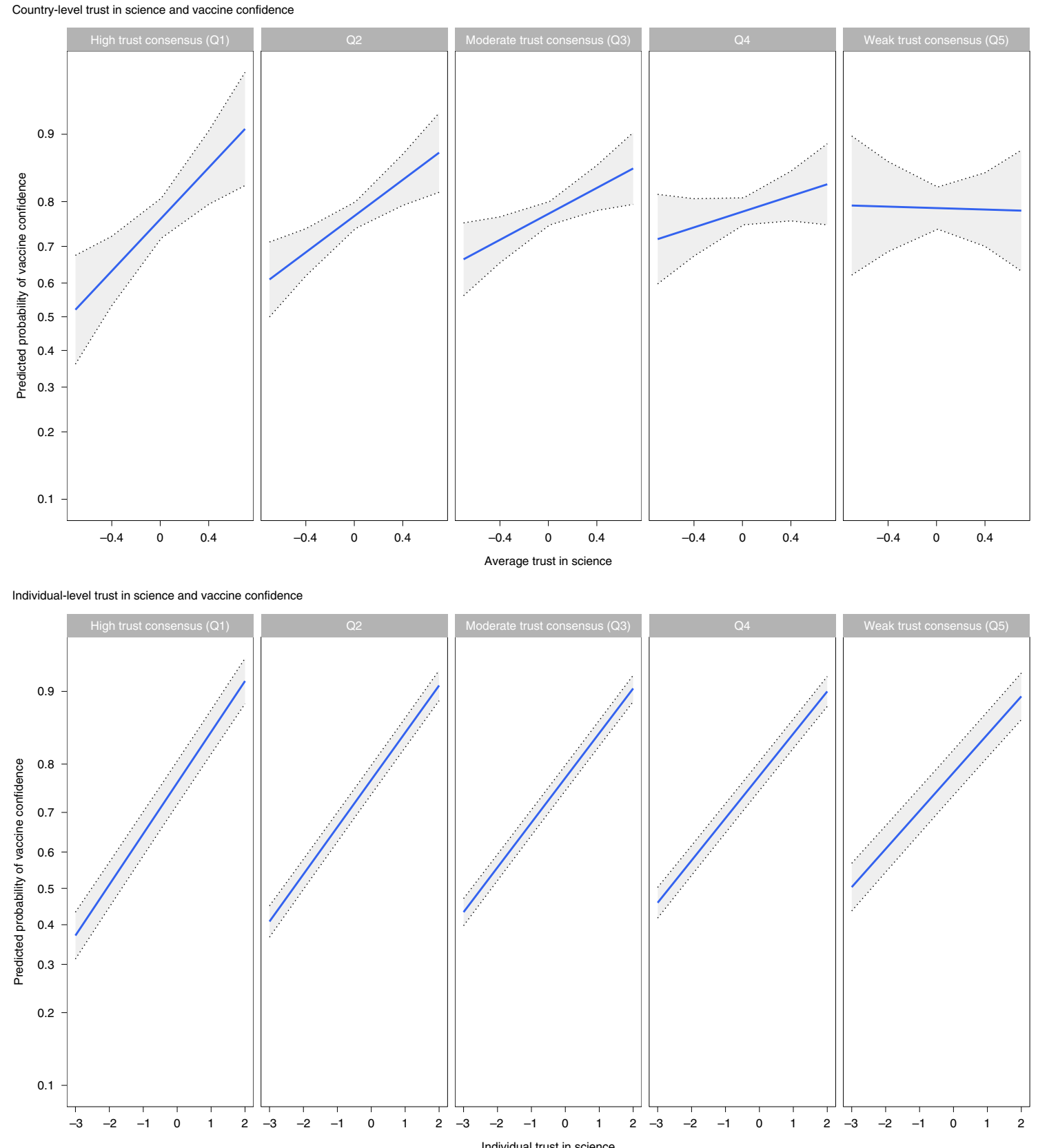

Fig. 2 | The strength of consensus around trust moderates the relationship between trust in science and support for vaccines. The data are from the 2018 Wellcome Global Monitor survey $(N=108,764)$. The data points are fitted values from model $1 \mathrm{~b}$ in Table 2 ; the grey shaded areas are $95 \%$ confidence intervals. The vertical axes are plotted using a logit scale. Q1 through Q5 are quintiles of social consensus on trust in science (Q1 is the top quartile, Q5 is the bottom quartile).

across the world. However, it is well known that for vaccines to be effective in controlling and eliminating viruses, they not only need to protect individuals from infection but must also be taken by a sufficiently large proportion of the population to attain herd immunity $^{31}$. Worryingly, recent surveys have revealed substantial minorities in many countries who say they are unlikely to be vaccinated, even when a safe and effective vaccine is available-an example of what epidemiologists refer to as 'vaccine hesitancy'17. Given the crucial importance of achieving high rates of vaccination against coronavirus across the world (not just in countries that can afford the vaccine and have the infrastructure to administer it quickly at scale), it is essential that we better understand the individual and societal sources of vaccine hesitancy.
In this article, we have focused on the macro-level association between trust in science and vaccine confidence, a key component of vaccine hesitancy. Using representative survey data covering 126 countries, we have shown that both the average level of trust in science in a country and the variability around that average are important in understanding individual-level vaccine confidence. Our results suggest that, as with the protective effects of vaccines, public confidence in immunization programmes is related to factors operating at the community level as well as the individual level.

It should be acknowledged that the Wellcome Global Monitor data were collected before the start of the COVID-19 pandemic, so we must be cautious about extrapolating these findings to the current extraordinary context. Nonetheless, while a replication of these 
analyses on data collected during the pandemic would clearly be of value, there is no strong reason to assume that our core findings should not also be evident in the specific case of coronavirus vaccination. Our findings and conclusions are also based on cross-sectional data, and we therefore cannot impose causal interpretations on the associations between variables that we have observed at both the country and individual levels.

Our key finding is that, in countries where trust in science is high, people are also more confident about vaccination, even accounting for their own level of trust in science. We have also shown that the strength of the social consensus in a country that science and scientists are trustworthy moderates the macro-level and micro-level relationships between trust in science and vaccine confidence: in countries where the consensus that science and scientists can be trusted is high, the positive association between trust in science and vaccination confidence is stronger. This moderating relationship is apparent when considering both the between-country and the within-country associations between trust in science and vaccine confidence, albeit considerably more weakly for individual-level trust in science. Our findings point to the importance of looking beyond individual-level correlates of vaccine confidence to incorporate a consideration of how norms of trust and mistrust of science are produced and maintained in different social contexts. An important avenue for future research will be to identify factors that contribute to the production of societal consensus around trust in science to inform effective public communication strategies around vaccination programmes.

\section{Methods}

The data for this study come from the 2018 Wellcome Global Monitor, which was carried out as part of the Gallup World Poll ${ }^{32}$, an annual cross-national survey of adults aged $15+$ living in households at non-institutional addresses. The achieved sample size was approximately 1,000 in each of the 144 countries, rising to 2,000 for China, India and Russia. The data for Cyprus and Northern Cyprus were combined to enable linkage to the country-level variables that we include in our models. Seventeen countries could not be included in the analysis because they had missing values on the survey variables (2), on the country level variables (14) or both (1). To check the sensitivity of our findings to the exclusion of these countries, we also fitted models using multiple imputation of these missing data. These models produced the same substantive results and are included in Supplementary Tables 2 and 3.

In countries with at least $80 \%$ phone coverage, interviews were carried out via computer-assisted telephone interviewing, with face-to-face interviewing used in the remaining countries. For telephone interviews, sampling was implemented through either random digit dialling or simple random sampling from nationally representative lists of numbers. Dual frame sampling was used in countries with high rates of mobile phone penetration. Sampling for in-home interviews was implemented in two stages, where the first stage selected primary sampling units with probability proportional to population size and the second stage selected a random sample of households within each primary sampling unit, using the random route method.

The source questionnaire was produced in English, Spanish and French and then translated using local translators into every language spoken by more than $5 \%$ of the resident population in each country using back translation ${ }^{33}$. A comparison of country-level estimates across a range of indicators between the Gallup World Poll, the European Social Survey and the European Union Statistics on Income and Living Conditions found high levels of correspondence, with correlations in the range 0.87 $0.91\left(\right.$ ref. $\left.{ }^{34}\right)$. Further details on the design and fieldwork procedures of the Wellcome Global Monitor can be found in the Gallup World Poll technical report ${ }^{35}$.

Vaccine confidence is measured using three items from the vaccine confidence scale developed by Larson et al., which ask respondents to state their level of agreement on a strongly-agree-to-strongly-disagree scale that vaccines are important for children to have, safe and effective $\mathrm{e}^{21}$. The fourth item from the vaccine confidence scale, which asks whether vaccination is consistent with the respondent's religious beliefs, was not included in the Wellcome Global Monitor. Due to the high rates of agreement to these items, and following de Figueiredo et al. ${ }^{36}$, they are recoded to binary variables indicating vaccine confidence, where agree/strongly agree $=1$ and all other responses $=0\left(\right.$ ref. $\left.{ }^{36}\right)$. A combined measure of overall vaccine confidence was then derived by coding respondents as 1 who agree/strongly agree to all three items and 0 otherwise. The models are fitted for the combined item and for the three items separately.

Trust in science is measured using seven questions. Three ask respondents to state the extent that they trust scientists in this country, trust science and trust scientists to find out accurate information about the world. The remaining four items ask respondents how much they trust (1) scientists working in colleges or universities and (2) scientists working for companies making medicines or agricultural products to (a) do their work with the intention of benefiting the public and (b) be open and honest about who is paying for their work. Response options for these questions were: a lot, some, not much, not at all. The seven items were combined into a single score using an IRT model ${ }^{37}$. For $i=1, \ldots, I$ polytomous items with $k$ ordered categories, the probability of observing outcome $k$ or higher for item $i$ and person $j$ is given by

$$
\operatorname{Pr}\left(Y_{i j} \geq k \mid \theta_{j}\right)=\frac{\exp \left\{\alpha_{i}\left(\theta_{j}-b_{i k}\right)\right\}}{1+\exp \left\{\alpha_{i}\left(\theta_{j}-b_{i k}\right)\right\}}, \theta_{j} \sim N(0,1)
$$

where $\alpha_{i}$ is the discrimination of item $i, b_{i k}$ is the difficulty of responding with category $k$ or higher and $\theta_{j}$ is the latent trait measuring overall trust in science. The results for this model are included in Supplementary Table 1.

The Wellcome Global Monitor also includes a question on trust in medical and health advice from medical workers. To assess the robustness of our findings, we also fitted models using these items instead of the seven-item trust scale, and this produced the same pattern of results (Supplementary Tables 4 and 5).

In addition to our focus on individual and country levels of trust in science, we assess how the strength of societal consensus that science can be trusted is related to vaccine confidence. We operationalize the strength of societal consensus as the within-country heterogeneity around the average level of scientific trust. In countries where the standard deviation of the trust measure is smaller, we take this as indicating greater consensus between citizens that science and scientists can be trusted, and vice versa (see refs. ${ }^{13,15}$ for existing applications of this approach).

To model country-level heterogeneity in the mean and standard deviation of trust in science, we use a mixed-effects location-scale model ${ }^{38,39}$, which has the following form (let $y_{i j}$ denote the trust in science score for individual $i\left(i=1, \ldots, n_{j}\right)$ living in country $j(j=1, \ldots, J))$ :

$$
y_{i j}=\mathbf{x}_{i j}^{\prime} \boldsymbol{\beta}+u_{j}^{[1]}+e_{i j}
$$

where $\mathbf{x}_{i j}^{\prime}$ is a vector of individual- and country-level covariates with coefficient vector $\boldsymbol{\beta}, u_{j}^{[1]}$ is a random intercept representing unobserved influences common to all individuals in country $j$, and $e_{i j}$ is the level-1 residual. Unlike a standard two-level model, we relax the assumption of a common level-1 variance by specifying an auxiliary $\log$-linear equation for the level-1 standard deviation, $\sigma_{e}$, as a function of covariates and an additional country random effect (our focus on the standard deviation reflects the location-scale model implementation in $\mathrm{R}$, which differs from some existing applications where the variance is used, although in practice this choice has little effect on the substantive interpretation of model parameters):

$$
\ln \left(\sigma_{e_{i j}}\right)=\mathbf{w}_{i j}^{\prime} \boldsymbol{\alpha}+u_{j}^{[2]}
$$

Here $\ln \left(\sigma_{e_{i j}}\right)$ is the log of the now-heterogeneous within-country standard deviation, $\mathbf{w}_{i j}^{\prime}$ is a vector of individual-level and country-level covariates with coefficient vector $\boldsymbol{\alpha}$, and $u_{i}^{[2]}$ is an additional country random effect. The [2] superscript distinguishes this random effect from the country-level random effect in equation (2). Positive coefficients in $\boldsymbol{\alpha}$ indicate characteristics associated with more variable trust in science assessments, while negative coefficients indicate the opposite. The location and scale random effects are assumed to have bivariate normal distributions and are allowed to covary. These can then be used to derive posterior estimates of the country-specific residuals, $\hat{u}_{j}^{[1]}$ and $\hat{u}_{j}^{[2]}$. It would be preferable to include the IRT model as part of the location-scale model, because failure to do this means that we do not properly account for random errors in the individual-level fitted values. However, it is not possible to include latent variables in this way using currently available software, and we consider it unlikely that this has any notable effect on our main results and conclusions.

A positive covariance between location and scale effects can be induced where the distribution of the response variable is skewed as a result of 'floor' or 'ceiling' effects $^{40}$. However, this is not a concern here because the distributions of the mean and variance in trust in science across countries is normally distributed and the correlation between the posterior residuals is just 0.140 (the correlation for the unadjusted residuals is -0.198 ).

We control for characteristics of individuals and countries that might be correlated with both trust in science and vaccine confidence, with our selection of variables guided by existing cross-national studies of trust in science and vaccine confidence ${ }^{36,41}$. We have opted for a parsimonious model specification to maximize the number of countries available for analysis, given the large amount of missing data on the country-level variables. At the country level, we control for gross domestic product per capita, the Gini measure of income inequality (www. worldbank.org) and the Harmonized Learning Outcome ${ }^{42}$. All country-level measures are standardized to aid interpretation. At the individual level, we include controls for sex, age, education level and logged income. Models are estimated in Stan using the R package BRMS with uninformative priors and a total of four chains and 20,000 iterations each ${ }^{43}$.

To assess how individual-level and country-level trust in science are related to confidence in vaccination, we fit multilevel binary logistic regression models ${ }^{10}$ including the posterior residuals from the location and scale equations measuring overall trust and consensus at level 2 : 
$\log \left(\frac{\pi_{i j}}{1-\pi_{i j}}\right)=\beta_{0 j}+\beta_{1} x_{1 i j}+\beta_{2} \hat{u}_{j}^{[1]}+\beta_{3} \hat{u}_{j}^{[2]}+\beta_{4} \hat{u}_{j}^{[1]} \hat{u}_{j}^{[2]}+\beta_{5} x_{1 i j} \hat{u}_{j}^{[2]}+u_{j}$

where $\pi_{i j}$ is the probability that individual $i$ in country $j$ is vaccine confident, $x_{1 i j}$ is trust in science for individual $i$ in country $j, \hat{u}_{i}^{[1]}$ is the residual difference from the mean level of trust in science for country $j, \hat{u}_{j}^{[2]}$ is the residual difference on the scale equation (our measure of societal consensus) for country $j, u_{j}$ is the country-level random effect and $\beta_{1}$ to $\beta_{5}$ are the regression coefficients.

Reporting Summary. Further information on research design is available in the Nature Research Reporting Summary linked to this article.

\section{Data availability}

The Wellcome Global Monitor dataset (https://doi.org/10.5255/UKDA-SN-8466-2) used in this paper can be downloaded from the UK Data Service website at https:// beta.ukdataservice.ac.uk/datacatalogue/studies/study?id=8466.

\section{Code availability}

The $\mathrm{R}$ code used to fit the models in this paper is available via GitHub at https://github.com/PatrickSturgis/

Trust-in-science-social-consensus-and-vaccine-confidence.

Received: 10 August 2020; Accepted: 13 April 2021;

Published online: 17 May 2021

\section{References}

1. Ritchie, H. et al. Coronavirus (COVID-19) vaccinations. Our World in Data https://ourworldindata.org/covid-vaccinations (2021).

2. Heesterbeek, H. COVID-19 will probably become endemic-here's what that means. The Conversation https://theconversation.com/covid-19-will-probabl y-become-endemic-heres-what-that-means-146435 (2020).

3. Randolph, H. E. \& Barreiro, L. B. Herd immunity: understanding COVID-19. Immunity 52, 737-741 (2020).

4. Lazarus, J. V. et al. A global survey of potential acceptance of a COVID-19 vaccine. Nat. Med. https://doi.org/10.1038/s41591-020-1124-9 (2020).

5. G7 countries perception of COVID-19, Wave 3. Kantar https://www.kantar. com/inspiration/politics/citizen-impact-covid19-infographic (2020).

6. COVID-19: Global Attitudes Towards a COVID-19 Vaccine (Institute of Global Health Innovation, 2020); https://www.imperial.ac.uk/media/imperial-college/ institute-of-global-health-innovation/GlobalVaccineInsights_ICL-Covid19-Behaviour-Tracker-EMBARGOED-00.01-04.02.2021.pdf

7. Markel, H. Taking shots: the modern miracle of vaccines. Medscape www.medscape.com/viewarticle/481059 (2004).

8. Poland, G. A. \& Jacobson, T. M. The age-old struggle against the antivaccinationists. N. Engl. J. Med. 364, 97-99 (2011).

9. Larson, H. J. et al. Measuring trust in vaccination: a systematic review. Hum. Vaccin. Immunother. 14, 1599-1609 (2018).

10. Goldstein, H. Multilevel Statistical Models (Wiley, 2011).

11. Gelman, A. Red State, Blue State, Rich State, Poor State: Why Americans Vote the Way They Do (Princeton Univ. Press, 2008).

12. Fairbrother, M. Trust and public support for environmental protection in diverse national contexts. Sociol. Sci. 3, 359-382 (2016).

13. Browning, C. R., Dirlam, J. \& Boettner, B. From heterogeneity to concentration: Latino immigrant neighborhoods and collective efficacy perceptions in Los Angeles and Chicago. Soc. Forces 95, 779-807 (2016).

14. Downs, G. W. \& Rocke, D. M. Interpreting heteroscedasticity. Am. J. Polit. Sci. 23, 816-828 (1979).

15. Brunton-Smith, I., Sturgis, P. \& Leckie, G. How collective is collective efficacy? The importance of consensus in judgments about community cohesion and willingness to intervene. Criminology 56, 608-637 (2018).

16. Reynolds, K. J. Social norms and how they impact behaviour. Nat. Hum. Behav. 3, 14-15 (2019)

17. Larson, H. J. et al. Understanding vaccine hesitancy around vaccines and vaccination from a global perspective: a systematic review of published literature, 2007-2012. Vaccine 32, 2150-2159 (2014).

18. Strategic Advisory Group of Experts on Immunization (SAGE) Report of the SAGE Working Group on Vaccine Hesitancy (WHO, 2014); www.who.int immunization/sage/meetings/2014/october/SAGE_working_group_revised_ report_vaccine_hesitancy.pdf?ua=1

19. Macdonald, N. E. \& SAGE Working Group on Vaccine Hesitancy. Vaccine hesitancy: Definition, scope and determinants. Vaccine 33, 4161-4164 (2015).

20. Larson, H. J. The state of vaccine confidence 2016: global insights through a 67-country survey. EBioMedicine 12, 295-301 (2016).

21. Larson, H. J., Schulz, W. S., Tucker, J. D. \& Smith, D. M. D. Measuring vaccine confidence: introducing a global vaccine confidence index. PLoS Curr. Outbreaks https://doi.org/10.1371/currents.outbreaks. ce0f6177bc97332602a8e3fe7d7f7cc4 (2015).
22. Cummings, L. The 'trust' heuristic: arguments from authority in public health. Health Commun. 29, 1043-1056 (2014).

23. Barber, B. Trust in science. Minerva 25, 123-134 (1987).

24. Merk, C. \& Pönitzsch, G. The role of affect in attitude formation toward new technologies: the case of stratospheric aerosol injection. Risk Anal. 37/12, 2289-2304 (2017).

25. Midden, C. J. \& Huijts, N. The role of trust in the affective evaluation of novel risks: the case of $\mathrm{CO}_{2}$ storage. Risk Anal. 29/5, 743-751 (2009).

26. Buskens, V. \& Weesie, J. An experiment on the effects of embeddedness in trust situations: buying a used car. Rationality Soc. 12, 227-253 (2000).

27. Barrera, D. \& Buskens, V. Imitation and learning under uncertainty: a vignette experiment. Int. Sociol. 22, 367-396 (2007).

28. Rothstein, B. Trust, social dilemmas and collective memories. J. Theor. Polit. 12, 477-501 (2000).

29. Ostrom, E. in Trust and Reciprocity: Interdisciplinary Lessons from Experimental Research (eds Ostrom, E. \& Walker, J.) 19-79 (Russell Sage Foundation, 2003).

30. Wellcome Global Monitor-First Wave Findings (Gallup, 2019); https://wellcome.org/reports/wellcome-global-monitor/2018

31. Fine, P., Eames, K. \& Heymann, D. 'Herd immunity': a rough guide. Clin. Infect. Dis. 52, 911-916 (2011).

32. Gallup World Poll (Gallup, 2018).

33. Harkness, J. in Cross-Cultural Survey Methods (eds Harkness, J. et al.) 35-56 (Wiley, 2002).

34. Holmqvist, G. \& Natali, L. Exploring the Late Impact of the Great Recession Using Gallup World Poll Data Innocenti Working Paper No. 2014-14 (UNICEF Office of Research, 2014).

35. Worldwide Methodology and Codebook (Gallup, 2017); https://data-services. hosting.nyu.edu/wp-content/uploads/2017/10/World_Poll_ Methodology 102717.pdf

36. de Figueiredo, A. et al. Mapping global trends in vaccine confidence and investigating barriers to vaccine uptake: a large-scale retrospective temporal modelling study. Lancet 396, 898-908 (2020).

37. Lord, F. M. Applications of Item Response Theory to Practical Testing Problems (Lawrence Erlbaum Associates, 1980).

38. Hedeker, D., Mermelstein, R. J. \& Demirtas, H. An application of a mixed-effects location scale model for analysis of ecological momentary assessment (EMA) data. Biometrics 64, 627-634 (2008).

39. Leckie, G., French, R., Charlton, C. \& Browne, W. J. Modeling heterogeneous variance-covariance components in two-level models. J. Educ. Behav. Stat. 39, 307-332 (2014)

40. Jackson, J. et al. Police legitimacy and the norm to cooperate: using a mixed effects location-scale model to estimate social norms at a small spatial scale. J. Quant. Criminol. https://doi.org/10.1007/s10940-02009467-5 (2020).

41. Huber, B. et al. Fostering public trust in science: the role of social media. Public Underst. Sci. 28, 759-777 (2019).

42. Angrist, H. A. \& Angrist, N. Global Dataset on Education Quality: A Review and Update (2000-2017) Policy Research Working Paper No. WPS 8592 (World Bank Group, 2018).

43. Buerkner, P.-C. brms: an R package for Bayesian multilevel models using Stan. J. Stat. Softw. 80, 1-28 (2018).

\section{Acknowledgements}

The authors received no specific funding for this work.

\section{Author contributions}

All authors made full and substantial contributions. P.S. contributed to conceptualization, writing, reviewing and editing; I.B.-S. contributed to data processing and analysis, writing and editing; and J.J. contributed to conceptualization and writing.

\section{Competing interests}

The authors declare no competing interests.

\section{Additional information}

Supplementary information The online version contains supplementary material available at https://doi.org/10.1038/s41562-021-01115-7.

\section{Correspondence and requests for materials should be addressed to P.S.}

Peer review information Nature Human Behaviour thanks Gretchen Chapman, Heidi Larson, Eitan Tzelgov and the other, anonymous, reviewer(s) for their contribution to the peer review of this work.

Reprints and permissions information is available at www.nature.com/reprints.

Publisher's note Springer Nature remains neutral with regard to jurisdictional claims in published maps and institutional affiliations

(c) The Author(s), under exclusive licence to Springer Nature Limited 2021 


\section{Reporting Summary}

Nature Research wishes to improve the reproducibility of the work that we publish. This form provides structure for consistency and transparency in reporting. For further information on Nature Research policies, see our Editorial Policies and the Editorial Policy Checklist.

\section{Statistics}

For all statistical analyses, confirm that the following items are present in the figure legend, table legend, main text, or Methods section.

n/a Confirmed

Х $\square$ The exact sample size $(n)$ for each experimental group/condition, given as a discrete number and unit of measurement

Х $\square$ A statement on whether measurements were taken from distinct samples or whether the same sample was measured repeatedly

The statistical test(s) used AND whether they are one- or two-sided

$\bigotimes$ Only common tests should be described solely by name; describe more complex techniques in the Methods section.

$\bigotimes$ A description of all covariates tested

$\bigotimes \square$ A description of any assumptions or corrections, such as tests of normality and adjustment for multiple comparisons

$\searrow$ A full description of the statistical parameters including central tendency (e.g. means) or other basic estimates (e.g. regression coefficient)

$\bigotimes$ AND variation (e.g. standard deviation) or associated estimates of uncertainty (e.g. confidence intervals)

$\varnothing$ For null hypothesis testing, the test statistic (e.g. $F, t, r$ ) with confidence intervals, effect sizes, degrees of freedom and $P$ value noted

Give P values as exact values whenever suitable.

$\square$ \ For Bayesian analysis, information on the choice of priors and Markov chain Monte Carlo settings

$\square \bigotimes$ For hierarchical and complex designs, identification of the appropriate level for tests and full reporting of outcomes

Х $\square$ Estimates of effect sizes (e.g. Cohen's $d$, Pearson's $r$ ), indicating how they were calculated

Our web collection on statistics for biologists contains articles on many of the points above.

\section{Software and code}

Policy information about availability of computer code

Data collection Not applicable (the analysis uses secondary data)

Data analysis Models are estimated in Stan using the R package BRMS (Buerkner, 2017).

For manuscripts utilizing custom algorithms or software that are central to the research but not yet described in published literature, software must be made available to editors and reviewers. We strongly encourage code deposition in a community repository (e.g. GitHub). See the Nature Research guidelines for submitting code \& software for further information.

\section{Data}

Policy information about availability of data

All manuscripts must include a data availability statement. This statement should provide the following information, where applicable:

- Accession codes, unique identifiers, or web links for publicly available datasets

- A list of figures that have associated raw data

- A description of any restrictions on data availability

The Wellcome Global Monitor data set (http://doi.org/10.5255/UKDA-SN-8466-2) used in this paper can be downloaded from the UK Data Service website here: https://beta.ukdataservice.ac.uk/datacatalogue/studies/study?id=8466 


\section{Field-specific reporting}

Please select the one below that is the best fit for your research. If you are not sure, read the appropriate sections before making your selection.
Life sciences
Вehavioural \& social sciences
Ecological, evolutionary \& environmental sciences

For a reference copy of the document with all sections, see nature.com/documents/nr-reporting-summary-flat.pdf

\section{Behavioural \& social sciences study design}

All studies must disclose on these points even when the disclosure is negative.

Study description

The data are a quantitative cross-national survey of individuals.

Research sample

We use the Wellcome Global Monitor survey, which is a cross-national survey of representative sample of individuals in 140 countries carried out in 2018 by Gallup. This study was chosen because it gives the best available coverage of countries of any survey measuring vaccine hesitancy.

Sampling strategy

Data for this study come from the 2018 Wellcome Global Monitor, which was carried out as part of the Gallup World Poll (GWP), an annual cross-national survey of adults aged $15+$ living in households at non-institutional addresses. The achieved sample size was approximately 1,000 in each of the 125 countries with complete country-level data, rising to 2,000 for China, India, and Russia. Sampling for in-home interviews is implemented in 2-stages, where the first stage selects primary sampling units (PSU) with probability proportional to population size and the second stage selects a random sample of households within each PSU, using the random route method.

Data collection

In countries with at least $80 \%$ phone coverage, interviews were carried out via Computer Assisted Telephone interviewing, with faceto-face interviewing used in the remaining countries. For telephone interviews, sampling is implemented through either Random Digit Dialling (RDD) or simple random sampling from nationally representative lists of numbers. Dual frame sampling is used in countries with high rates of mobile phone penetration.

Timing

Data were collected between April and December 2018

Data exclusions

The full data set contains 149,014 individuals within 143 countries. The analysis included 122,007 individuals in 125 countries. 18 countries were dropped because they did not have complete data for HLO, Gini, and GDP. An additional 17461 individuals were dropped because they did not provide valid responses to the trust in science and/or the vaccine confidence questions.

Non-participation This is a secondary data set which is made available through the UK Data Service. The funder of the survey has not published response rates for the country surveys.

Randomization There was no experimental randomization in the design.

\section{Reporting for specific materials, systems and methods}

We require information from authors about some types of materials, experimental systems and methods used in many studies. Here, indicate whether each material, system or method listed is relevant to your study. If you are not sure if a list item applies to your research, read the appropriate section before selecting a response.

\begin{tabular}{l} 
Materials \& experimental system \\
\hline $\mathrm{n} / \mathrm{a} \quad$ Involved in the study \\
$\square$ \\
$\square$ Antibodies \\
$\square$ \\
$\square$ \\
$\square$ Eukaryotic cell lines \\
$\square$ \\
$\square$ Palaeontology and archaeology \\
$\square$ Animals and other organisms \\
$\square$ \\
$\square$ Clinical data
\end{tabular}

\begin{tabular}{l|l} 
Methods \\
\hline n/a & Involved in the study \\
$\square$ & $\square$ ChIP-seq \\
$\searrow$ & $\square$ Flow cytometry \\
$\searrow$ & $\square$ MRI-based neuroimaging
\end{tabular}

